\title{
What's in the Book of Life?
}

\author{
Staffan Müller-Wille
}

\author{
What Genes Can't Do \\ By Lenny Moss \\ The MIT Press, Basic Bioethics series; $\$ 34.95$, \\ 258 pp, hardcover, ISBN 0-262-13411-X, 2002
}

With the publication of the draft sequence of the human genome in 2001, scholars interested in the development of science-be they historians, sociologists, or philosophershave the unique chance to study a major scientific revolution while it is actually going on. This revolution became palpable, as so often happens, with a shift of metaphors signaling the direction in which genetic research should go in the new era of postgenomics. Since the "blueprint of a human being," the "book of life" has now been opened-as the Human Genome Project international consortium stated in its public announcement of the completion of its draft sequence- "scientists are beginning to get a good sense of what the genome landscape looks like and the surprising stories it has to tell."

Lenny Moss's book What Genes Can't Dothe title recalls Hubert Dreyfus's What Computers Can't Do: The Limits of Artificial Intelligence - can be seen as an attempt to chart the historical legacy and conceptual issues at stake in the return to a developmental approach to genetics, as indicated by the shift from informational to ecological and architectural metaphors. His vantage point in this is clearly formulated: for him, the publication of the human genome sequence marks not only the "culmination" but also the "conclusion of the "century of the gene"' (p. 184). Moss diagnoses this century as one which, under the spell of information metaphors, fatefully conflated two separate gene concepts: “Gene-P," as he calls it, where some deviation in the genotype is correlated with a deviation of phenotype, so that it appears as if the former directly determined the latter (blue eyes, for example, are not made according to the directions of the gene for eye color, but result if this gene fails to produce the brown-eye pigment); and "GeneD," where genes function as developmental resources, as templates for the synthesis of proteins, but are indeterminate with respect to phenotype (as phenotypic outcome depends

Staffan Müller-Wille is a research fellow at the Max Planck Institute for the History of Science, Wilhelmstrasse 44, D-10117 Berlin, Germany(smuewi@mpiwg-berlin.mpg.de). on other, non-genetic factors as well). Gene-P is of instrumental utility in predicting a phenotypic outcome within a certain range of probability. Gene-D is a concept for elucidating the causal pathways involved in the development, physiology, and pathophysiology of the human body (p. 45-46).

Moss writes as a philosopher, but as one who attempts an empirically argued critique of both historical and current trends in genetics and its application. The result is a book that unites wealth of detail and clarity of exposition to an exceptional degree. The first two chapters provide a wide-ranging reconstruction of the two historical trends-preformationism and epigenesis - that form the legacies of the two gene concepts identified by Moss, and discuss how they were eventually combined in the concept of a hereditary "code-script" put forward by physicist Erwin Schrödinger in his influential book What is Life? These two chapters do not meet the standards of historiography, as they argue from hindsight. They are successful, however, in unfolding an array of alternatives to preformationist theories, alternatives suggested by major protagonists in the history of biology: comparative morphology, embryology of germ layers, cell theory, and cellular histopathology: that is, all of the major biological innovations of the 19th century, save Darwin's theory of evolution, were based on a heuristic groundwork that recognized the self-organizational nature of organisms but strove nevertheless to account for it by mechanistic analysis.

The "phylogenetic" turn-as Moss calls it-toward a new preformationism came with the rediscovery of Mendel's laws at the turn of the 20th century. Especially enjoyable reading is provided by the central section on Wilhelm Johannsen, who introduced the distinction between genotype and phenotype, but did so just to criticize this new preformationism. The section on Schrödinger's hereditary code-script gives this oft-discussed topic an interesting twist by showing that Schrödinger's argument can, indeed, be held empirically accountable, whereas the rhetorical tradition it instigated diverged more and more from empirical achievements in biochemistry and molecular biology.

With this, the scene is set for Moss to attack the conflation of "Gene-P" and "Gene-D" implied by the gene-as-text metaphor, on the basis of recent biological findings. Chapter 3 does this by characterizing three subcellular epigenetic systems-the membrane-based compartmentalization of the cell, the steadystate dynamics of regulatory processes at cell level, and the modulation of gene activity through DNA methylation-with the intention of demonstrating "that no one system, and certainly no molecule, could reasonably be accorded the status of being a program, blueprint, set of instructions, and so forth, for the remainder." Chapter 4, finally, turns to oncology as a particular research field whose development was initially fueled by a conflationary conception of the gene in the somatic mutation hypothesis, but unexpectedly provided some of the strongest evidence on behalf of the epigeneticist view. That today's leading specialists (such as Bert Vogelstein, whose work on colorectal cancer is extensively discussed) still cling to a genomic model of heritable susceptibility while progressively undercutting the hypothesis of chance mutations directly causing cancer reflects, Moss argues, an "unprecedented influence of the marketplace (in the form of highly touted genetic tests) on the biomedical research agenda" (p. 182).

Even in the highly technical language necessary to describe the most recent findings of biomedical research, Moss manages to be admirably clear and explicit. His audience, as indicated by the series title Basic Bioethics, is anyone who is concerned with the increasing role that biology plays in understanding ourselves. This book leaves the reader with a lot of open questions: where to go next, for example. If the basis on which the century of the gene built its successes is an unwarranted conceptual conflation, are we simply to dismiss this as a basis for future research and the public's understanding of it? Maybe, after all, the "book of life" metaphor, conflationary as it is, provides the basis for the continuation of a particularly fruitful oscillation between the preformationist and epigeneticist poles that have structured biological thinking since antiquity. And what metaphors could provide an alternative to the still-prevalent information metaphors? The architectural and ecological metaphors used in the Human Genome Project consortium's public announcement? Or the metaphor of "ad-hoc committees adjudicating critical decisions at the nodal points of organismic development," as Moss has it in the concluding chapter? That it leaves the reader with such questions is not a weakness of the book. Quite the contrary, it is its merit. 